\title{
A SBEM e a Produção de Conhecimento em Educação Matemática
}

\author{
SBEM and knowledge production for Mathematical Education
}

\author{
Neuza Bertoni Pinto* \\ ORDIC iD 0000-0002-9224-3020
}

\begin{abstract}
Resumo
Em finais dos anos de 1980, com a criação da SBEM (Sociedade Brasileira da Educação Matemática), ampliouse o espaço científico da Educação Matemática de novos tempos, tempos de declínio da Matemática moderna e de avanços tecnológicos, sobretudo tempos de questionamentos de saberes profissionais dos professores que ensinam Matemática. No âmbito dos questionamentos, a par da valorização dos aspectos subjetivos na formação do professor, destacam-se preocupações com a complexidade envolvida na caracterização dos saberes profissionais e a dificuldade de sistematizá-los em vista de sua transformação em saberes institucionalizados. Partindo do pressuposto de que saberes profissionais são aqueles que passaram por complexos processos de objetivação e sistematização até se tornarem institucionalizados e integrarem a formação de uma determinada profissão socialmente reconhecida, foram selecionados seis estudos seminais no intento de compreender que saberes foram considerados imprescindíveis para o professor ensinar Matemática nos tempos atuais. Os resultados apontam para uma formação não dispersa e fragmentada, capaz de expressar o sentido profissional apropriado ao novo século que coloque em sintonia saberes da ciência de referência com saberes das ciências da Educação, saberes para ensinar Matemática com arte e ciência, apropriados para a docência em um mundo em constante mudança.
\end{abstract}

Palavras-chave: História da Educação Matemática. SBEM. ENEM. Profissão docente. Saberes para ensinar Matemática.

\begin{abstract}
At the end of 1980s, with the creation of SBEM (Brazilian Society of Mathematical Education), the scientific space of Mathematical Education was expanded to new times, in which modern Mathematics declined and technological advances rose up, especially concerning the questioning of mathematics teachers' professional knowledge. Within the scope of these questionings, along with the appreciation of the subjective aspects in teacher's training, there are concerns about the complexity involved in the characterization of professional knowledge and the difficulty of systematizing them in face of their transformation into institutionalized knowledge. Based on the assumption that professional knowledges are those that have undergone complex processes of objectification and systematization until they become institutionalized and integrate the formation of a certain socially recognized profession, we selected six seminal studies in an attempt to understand what
\end{abstract}

\footnotetext{
* Doutora em Educação- USP/SP. Docente Colaboradora do Programa de Ensino de Matemática e Ciências- ICET -REAMEC- UFMT, Cuiabá/MT. Endereço para correspondência: Rua Professor Arthur Loyola, 85 - Apto 53. Cabral,Curitiba- Paraná - Brasil, CEP: 80035-100. E-mail: neuzabertonip@gmail.com
} 
knowledge was considered essential for the teacher to teach Mathematics nowadays. The results point out to the existence of a non-dispersed and fragmented formation, capable of expressing an appropriate professional sense for a new century, that puts in tune knowledge of the reference science with knowledge of educational sciences, Mathematics teaching knowledge with art and science and, suitable for teaching in an ever-changing world.

Keywords: History of Mathematics Education. SBEM. ENEM. Teaching Profession. Knowledge to teach Mathematics.

\section{Considerações iniciais}

No cenário educacional brasileiro dos anos de 1980, momento de redemocratização do país, ampliam-se as críticas aos cursos de formação inicial de professores. A extinção das Escolas Normais, gerada a partir da lei 5692/71, contribuía com o grande desfalque na preparação de professores para o ensino dos primeiros anos escolares, ainda não suplantado pelos cursos de Pedagogia, dada a ausência de organicidade dos conhecimentos considerados indispensáveis para o exercício da docência nas séries iniciais. Os cursos de Licenciatura permaneciam organizados no emblemático modelo $3+1$, herança que outorgava primazia às ciências de referência e secundarizava conhecimentos advindos das ciências da Educação.

Apesar da junção, no início da década de 1970, do antigo curso primário ao ginasial, essa nova configuração curricular parecia, ainda, não ter repercussão nos cursos de formação de professores que, em sua maioria, mesmo em cenário aparentemente democrático, continuavam marcados por uma disjunção cultural, com predomínio de uma cultura geral na formação do professor primário e de uma cultura especializada na formação do professor secundário, situação que vai se revelando problemática quando se trata de uma formação direcionada ao ensino da Matemática.

Lembra Chervel (1990) que a história das disciplinas escolares guarda consigo marcas de momentos de crise entre as ciências e, no caso da Matemática, os movimentos empreendidos para modernizá-la parecem não ter alcançado os resultados almejados na formação dos professores. Todo um legado que permitiu construir novas práticas para Matemática foi descrito por Valente (2008), desde a herança do nosso tataravô profissional militar, do bisavô preparador de apostilas, do avô profissional que especializou-se na arte de reunir método a conteúdo, e de nosso pai profissional que revolucionou o ensino com a introdução da Matemática moderna, formando uma unidade com partes outrora fragmentadas. Cenários nos quais a formação apresenta-se atrelada a um forte passado de continuidade em que saberes e identidades vão sendo amalgamados na cultura profissional.

Em texto mais recente no qual analisa historicamente os múltiplos movimentos que ao 
longo do século XX marcaram o campo da Educação Matemática, Valente (2016) relembra ações de Euclides Roxo e o debate inédito que perpassou seus escritos ao afirmar que não bastava ser matemático para ser um bom professor de Matemática.

Levando em conta não somente a lógica dos conteúdos, Roxo indica que, para além do saber matemático, haviam outros saberes envolvidos na profissão docente. A passagem do ensino da Matemática para a Educação Matemática constituiu-se, à época, um marco histórico da modernização do campo da Educação Matemática. Ao deslocar o foco dos conteúdos de instrução para as necessidades e possibilidades do aprendiz cria uma ponte entre o instruir e o educar revelando uma clara conexão da Matemática na escola com aspectos mais amplos da Educação.

Contudo, Valente (2016) assevera que, em tempos de MMM, essa modernização sofre impactos do estruturalismo levando a Matemática na escola a supervalorizar os conteúdos, porém, a partir de novos pressupostos.

\begin{abstract}
Nesse movimento, o sujeito que aprende reduz-se a estruturas cognitivas universais, mobilizadas em paralelo àquelas estruturas colocadas para serem ensinadas na nova organização da matemática escolar. Promove-se o deslocamento de uma educação matemática para um ensino de matemática. Não há um retorno às bases anteriores, às formas da instrução matemática, pois existe uma preocupação metodológica diferente dos primeiros tempos. Naqueles, a própria organização dos conteúdos e sua sequência já indicavam a didática, os modos de ensinar. No MMM, as preocupações didáticas são de outra natureza: envolvem o desafio de realizar transposições, de modo que as estruturas algébricas possam ter alguma concretude [...] (VALENTE, 2016, p. 19).
\end{abstract}

Como esse contexto de mudanças repercutiu na produção da Sociedade Brasileira de Educação Matemática (SBEM) que, na época, inaugurava um novo campo profissional e de pesquisa? Que marcas históricas deixou na produção de saberes profissionais do professor que ensina Matemática? Representou uma inflexão em relação aos saberes do professor que ensina Matemática? Anunciou uma nova identidade do professor que ensina Matemática?

Uma hipótese é que a criação dessa sociedade, em 1988, possibilitou ampliar, não apenas o campo da Educação Matemática, mas os questionamentos acerca dos saberes profissionais dos professores que ensinam Matemática, cujos vestígios encontram-se em Anais de seu principal evento, o ENEM, testemunha das mobilizações ocorridas na formação do professor que ensina Matemática.

Nessa mesma época, pesquisadores da educação demonstravam preocupação com a fragilidade da formação docente, a falta de conhecimento de como preparar professores para o século XXI, de dados de pesquisa que denunciavam a fragmentação e a incompletude do campo de formação (ANDRÉ, 2009). Sobre o campo de estudo da formação docente, André (2010, p. 175-176) mostra que, entre os anos de 1990 a 2000, houve um redirecionamento nos temas 
estudados na Pós-Graduação. Anteriormente centrados na formação inicial e continuada, as pesquisas passam a focalizar os saberes e as práticas docentes, o desenvolvimento e a identidade profissional.

Gatti (2014) discute a naturalização de arranjos disciplinares que privilegiavam, nas licenciaturas, determinados saberes em detrimento de outros, considerados fundamentais na docência.

No intento de compreender epistemologicamente esse campo tão complexo da profissão docente, Fiorentini, Passos e Limas (2016) buscam ampliar a discussão, realizando sucessivos mapeamentos e balanços sobre professores que ensinam Matemática.

No mapeamento referente a 2001 e $2012^{1}$, no qual foram examinadas centenas de teses de doutorado e dissertações de mestrado acadêmico e profissional, concluídas em programas credenciados pelas áreas de Educação e Ensino da CAPES, as análises preliminares apontam que os estudos nesse campo continuaram dispersos e sem identidade própria. Apontam também que, entre os focos de investigação, ainda pouco considerados nas pesquisas, encontra-se a identidade profissional, com um percentual reduzido de estudos (apenas 4\%) e que "os saberes e competências" foram temas que apresentaram grande representatividade em diferentes regiões, tanto na formação inicial, quanto na formação continuada.

A síntese de Cericato (2016), sobre a profissão docente, focaliza a preocupação com a complexidade envolvida na caracterização dos saberes profissionais, considerando a intencionalidade e o saber altamente especializado exigido pela profissão. Defende "uma base cultural forte, aliada aos conteúdos e contextos de ensino, didática e representações sobre o ser docente que contribuam para superar a polêmica histórica sobre saberes próprios do professor" (p. 285). Ao reiterar constatações de estudos anteriores, Nacarato (2016) ressalta a menor atenção dada à dimensão teórica nos estudos que tratam em abundância de material empírico. Observação que remete a uma escassez de sistematizações e processos que permitem a institucionalização dos saberes docentes, transformando-os em saberes profissionais.

No âmbito dessas preocupações, encontram-se indicadores de que a partir da década de 1990, os estudos acerca da formação de professores tendem a valorizar aspectos subjetivos da formação, saberes construídos na ação, ao mesmo tempo que sinalizam para a presença de dificuldades em sistematizá-los, tendo em vista sua transformação em saberes

\footnotetext{
${ }^{1} \mathrm{O}$ inventario compreende 858 trabalhos (92 dissertações de mestrado em programas de mestrado profissional, 177 teses de doutorado e 589 dissertações de mestrado em programas de mestrado acadêmico) produzidos, no período de 2001-2012, em 85 diferentes instituições brasileiras (FIORENTINI; PASSOS; LIMA, 2016, p. 8).
} 
institucionalizados. De fato, a literatura que circulou a partir da década de 1990, no Brasil, ${ }^{2}$ deu ênfase aos saberes construídos na prática como sendo os saberes que dão sentido a profissão docente. Os denominados saberes da experiência passaram a ocupar um lugar importante nas pesquisas que tratavam dos saberes profissionais, todavia, as dificuldades para formalizá-los pareciam, segundo Pimenta (1997), não se justificarem pela carga de subjetividade neles envolvida.

\begin{abstract}
A formação passa sempre pela mobilização de vários tipos de saberes: saberes de uma prática reflexiva, saberes de uma teoria especializada, saberes de uma militância pedagógica. O que coloca os elementos para produzir a profissão docente, dotando-a de saberes específicos que não são únicos, no sentido de que não compõem um corpo acabado de conhecimentos, pois os problemas da prática profissional docente não são meramente instrumentais, mas comportam situações problemáticas que requerem decisões num terreno de grande complexidade, incerteza, singularidade e de conflito de valores (PIMENTA, 1997, p. 12).
\end{abstract}

Essa impossibilidade de objetivação de saberes da prática tem sido discutida em estudos recentes sobre saberes profissionais da docência, desenvolvidos por pesquisadores do grupo ERHISE, sediado na Universidade de Genebra, Suíça ${ }^{3}$. De acordo com esses estudos há modos distintos de abordar os saberes da docência. Do ponto de vista da prática, temos os saberes da experiência; do ponto de vista profissional, os saberes formalizados - saberes objetivados que permitem sua sistematização e institucionalização. Saberes profissionais, saberes que constituem o ethos da profissão docente, seriam aqueles que passaram por complexos processos de objetivação e sistematização até se tornarem institucionalizados e integrarem a formação de uma determinada profissão socialmente reconhecida (HOFSTETTER \& SCHNEUWLY, 2009). Partindo destes parâmetros, os saberes profissionais, aqueles que dizem respeito aos saberes de formação de professores, são concebidos como resultantes da articulação de um saber disciplinar, saberes a ensinar, objeto de trabalho da docência, advindos de uma ciência de referência e os saberes para ensinar, as ferramentas do ofício professoral, saberes filiados às ciências da educação (LUSSI BORER, 2017).

Como a produção da SBEM tem abordado a questão dos saberes profissionais e da identidade do educador matemático?

\title{
2 Encaminhamentos teórico-metodológicos
}

Um primeiro procedimento dessa pesquisa foi reunir registros dessa produção. Ficamos

\footnotetext{
${ }^{2}$ Dentre outras, a obra de Tardif (2002) sobre saberes profissionais docentes teve grande repercussão no Brasil.

${ }^{3}$ Sobre estudos desenvolvidos pelo grupo suíço ERHISE, ver Hofstetter e Valente (2017).
} 
surpresas com a organização do $\operatorname{site}^{4}$ que disponibiliza preciosas fontes históricas, dentre outras, aquelas que supúnhamos portadoras de vestígios da produção a ser investigada, como os Anais dos eventos que realiza, o Encontro Nacional de Educação Matemática (ENEM) e o Seminário Internacional de Pesquisa em Educação Matemática (SIPEM), as edições dos periódicos que publica, Educação Matemática em Revista (EMR) e International Journal for Research in Mathematics Education (RIPEM).

Consultados os arquivos e realizados os inventários ${ }^{5}$ e mediante a quantidade de trabalhos da produção inventariada optamos por examinar, nessa primeira avaliação, apenas os Anais do ENEM, evento que, no período demarcado, produziu 12 edições constituindo-se no maior evento da Sociedade Brasileira de Educação Matemática (Quadro1).

\begin{tabular}{|l|l|l|l|}
\hline Evento & Ano & Local & Trabalhos \\
\hline I ENEM & 1987 & São Paulo/SP & 122 \\
\hline II ENEM & 1988 & Maringá/PR & 163 \\
\hline III ENEM & 1990 & Rio Grande do Norte & 185 \\
\hline IV ENEM & 1992 & Blumenau/SC & 182 \\
\hline V ENEM & 1995 & Aracaju /SE & 277 \\
\hline VI ENEM & 1998 & São Leopoldo/RS & 520 \\
\hline VII ENEM & 2001 & Rio de Janeiro/RJ & 399 \\
\hline VIII ENEM & 2004 & Recife/PE & 479 \\
\hline IX ENEM & 2007 & Belo Horizonte/MG & 667 \\
\hline X ENEM & 2010 & Salvador/BA & 1179 \\
\hline XI ENEM & 2013 & Curitiba/PR & 1503 \\
\hline XII ENEM & 2016 & São Paulo/SP & 1259 \\
\hline
\end{tabular}

Quadro 1 - Produção do ENEM (1987-2017)

Fonte: $\mathrm{O}$ autor (2018)

Na elaboração do inventário, buscou-se destacar, na totalidade dos trabalhos de cada edição, os temas que tiveram maior número de estudos e, na medida do possível, agrupar trabalhos de acordo com a organização categorial do evento. No entanto, dada a diversidade categorial $^{6}$, a organização pensada ficou inviabilizada. Contudo, o levantamento permitiu sumariamente conhecer temas em maior número de trabalhos submetidos ao longo do período, o que facilitou o próximo passo, ou seja, selecionar estudos relacionados à formação de professores.

\footnotetext{
${ }^{4}$ http://www.sbembrasil.org.br/sbembrasil/index.php/anais/enem

${ }^{5} \mathrm{Na}$ primeira etapa da pesquisa, além da produção apresentada nos ENENs, foram inventariadas produções localizadas em outras fontes históricas, dentre elas, a produção do Seminário Internacional de Pesquisa em Educação Matemática - SIPEM e dos periódicos Educação Matemática em Revista (EMR) e International Journal for Research in Mathematics Education (RPEM), que não fizeram parte do corpus de análise dessa pesquisa que representa uma primeira, das muitas análises que provavelmente virão na continuidade do presente estudo. Para o levantamento das fontes contamos com o trabalho de pesquisadores do GHEMAT PR, professoras Alexsandra Câmara, Antonio Flávio Claras, Bárbara Winniarski Diesel Novaes, Danilene Donim Berticelli, Iara da Silva França, Lidiane dos Santos Felisberto e Mariliza Simonete Portela.

${ }^{6}$ Em cada edição, a distribuição dos trabalhos era feita de acordo com os critérios definidos pela comissão organizadora. A edições da década de 1990 não apresentaram grandes variações quando comparadas com as edições da década seguinte.
} 
No prosseguimento foram realizadas leituras analíticas a partir dos trabalhos selecionados, ou seja, estudos que focalizando formação de professores, apresentavam discussões sobre saberes profissionais, priorizados no período marcado pelo declínio do Movimento da Matemática e chegada de novos questionamentos acerca dos saberes indispensáveis para ensinar Matemática.

\title{
3 A força do ENEM: um poderoso espaço de divulgação da produção em Educação
} Matemática

Com o objetivo de reunir profissionais de diferentes áreas: matemáticos, pedagogos, psicólogos, professores dos $1^{\circ}, 2^{\circ}$ e $3^{\circ}$ graus, bem como pesquisadores em Educação Matemática, ou áreas afins, o ENEM, desde sua criação, buscava além de caminhos para a melhoria da Matemática em todos os níveis, propiciar troca de experiências entre os participantes, bem como divulgar tendências atuais em Educação Matemática, assim como caracteriza-la como uma área de estudos de caráter interdisciplinar e com objeto próprio de pesquisa (ANAIS do X ENEM).

Com trinta anos de existência, o evento primogênito da SBEM, em suas 12 edições foi acolhido com muito otimismo por diferentes estados brasileiros. O I ENEM foi realizado na PUC de São Paulo, em 1987, ano que antecede a fundação da SBEM, criada em 27 de janeiro de 1988, como sociedade civil, de caráter científico e cultural, sem fins lucrativos e sem qualquer vínculo político, partidário ou religioso, cuja finalidade era congregar profissionais da área de Educação Matemática e de áreas afins (D’AMBRÓSIO, 1988, p. 8). Em sua abertura oficial, Ubiratan D'Ambrósio, cheio de otimismo, anuncia a chegada dos novos tempos da Educação Matemática.

\begin{abstract}
Todos aqueles diretamente envolvidos no processo tinham muito claro que uma vez realizado o I ENEM, com ampla participação nacional, estaria definida a continuação da série de congressos, e que o I ENEM era o passo essencial para deflagrar um processo democrático para a criação de uma Sociedade Brasileira de Educação Matemática, acolhendo todos aqueles prioritária e profissionalmente envolvidos com Educação Matemática no país e sobretudo uma sociedade sem dono pessoal ou institucional (D’AMBRÓSIO, 1988, p. 8).
\end{abstract}

A produção apresentada nas 12 edições do ENEM (Gráfico 1), nas décadas compreendidas entre 1987 e 2017, sinaliza a pujança da SBEM e a presença, em sua produção, de um movimento em busca da consolidação de uma nova identidade do professor que ensina Matemática: a do educador matemático. O maior número de trabalhos discutidos na década de 1990, após uma fase hegemônica centrada em torno de conteúdos matemáticos, tendo como 
prioridades a geometria e as novas metodologias advindas da tecnologia, seguidas da modelagem e resolução de problemas, ao que tudo indica, parece alinhar-se de forma crescente às novas concepções difundidas no Brasil, na área da formação de professores.

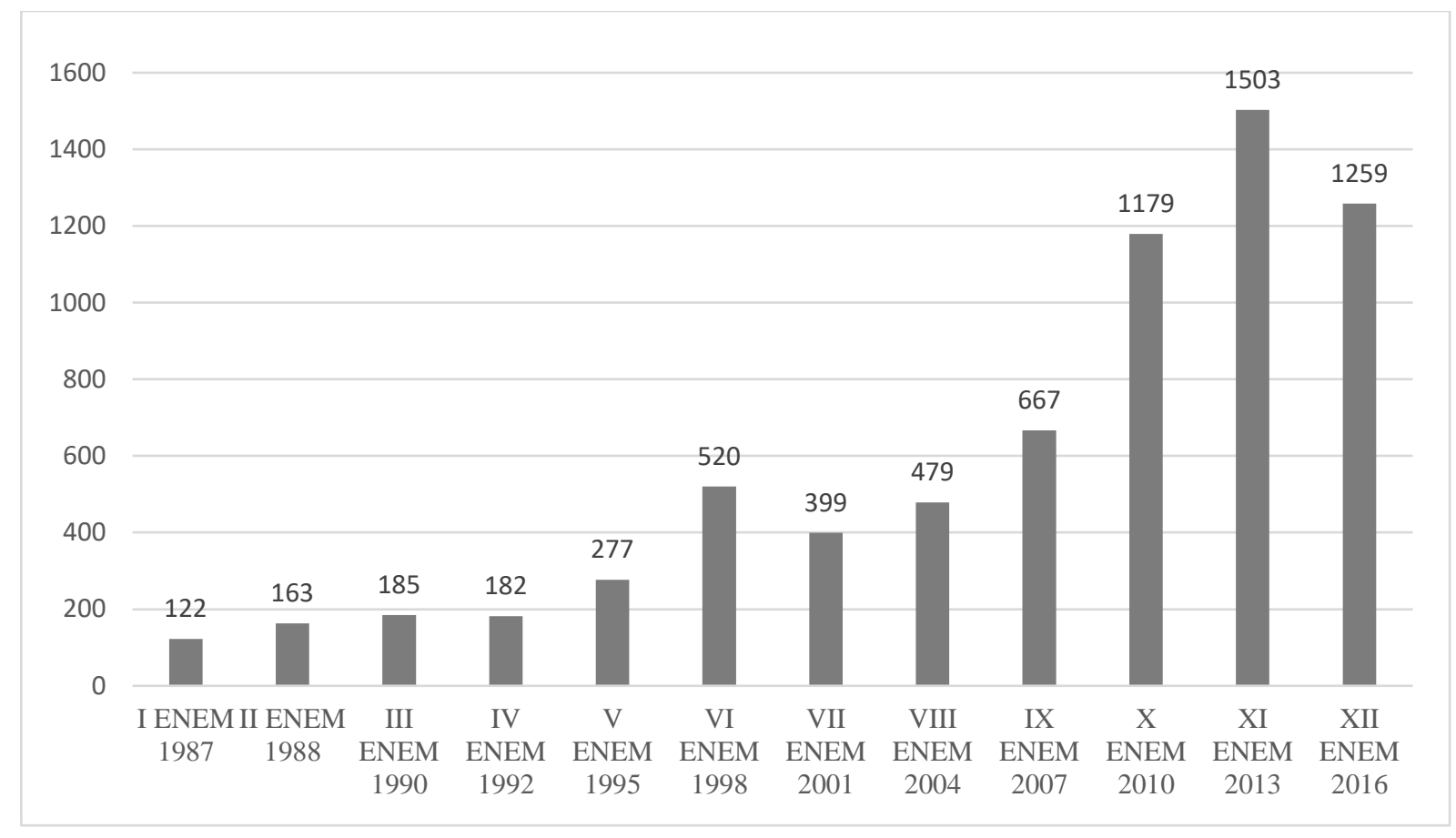

Gráfico 1 - Número de trabalhos em 12 edições do ENEM Fonte: $\mathrm{O}$ autor (2018)

\section{Saberes profissionais do professor que ensina Matemática}

A discussão sobre saberes próprios do professor que ensina Matemática, ao que indica essa primeira avaliação, produzida a partir de seis textos selecionados no quesito formação de professores, nas edições do ENEM, apesar de ainda tímida, contempla a temática dos saberes profissionais.

\begin{tabular}{|l|l|l|l|l|l|}
\hline Autor & Título & Categoria & ENEM & Ano & Local \\
\hline $\begin{array}{l}\text { D’AMBRÓSIO, } \\
\text { Ubiratan }\end{array}$ & $\begin{array}{l}\text { A educação matemática na } \\
\text { década de 1990: perspectivas e } \\
\text { desafios }\end{array}$ & $\begin{array}{l}\text { Conferência de } \\
\text { Abertura }\end{array}$ & I & 1987 & $\begin{array}{l}\text { São Paulo } \\
\text { SP }\end{array}$ \\
\hline $\begin{array}{l}\text { ROGÉRIO, Mauro } \\
\text { Urbano }\end{array}$ & $\begin{array}{l}\text { O que é específico na formação } \\
\text { do professor }\end{array}$ & $\begin{array}{l}\text { Comunicação } \\
\text { Científica }\end{array}$ & III & 1990 & $\begin{array}{l}\text { Natal } \\
\text { RN }\end{array}$ \\
\hline $\begin{array}{l}\text { BERTONI, Nilza } \\
\text { Eigenheer et al }\end{array}$ & $\begin{array}{l}\text { Síntese dos trabalhos sobre } \\
\text { formação e atualização de } \\
\text { professores }\end{array}$ & $\begin{array}{l}\text { Relatório- } \\
\text { Síntese G1 }\end{array}$ & V & 1995 & $\begin{array}{l}\text { Aracaju } \\
\text { SE }\end{array}$ \\
\hline $\begin{array}{l}\text { FIORENTINI, } \\
\text { Dario }\end{array}$ & $\begin{array}{l}\text { Do professor isolado ou plugado } \\
\text { ao professor conectado: novas } \\
\text { perspectivas à formação }\end{array}$ & $\begin{array}{l}\text { Mesa Redonda } \\
14\end{array}$ & VII & 2001 & $\begin{array}{l}\text { Rio } \\
\text { Janeiro } \\
\text { RJ }\end{array}$ \\
\hline $\begin{array}{l}\text { MONTEIRO, Ana } \\
\text { Clédina Rodrigues }\end{array}$ & $\begin{array}{l}\text { O que sei, quem sou e como atuo? } \\
\text { O curso de Licenciatura em }\end{array}$ & $\begin{array}{l}\text { Comunicação } \\
\text { Científica }\end{array}$ & X & 2010 & $\begin{array}{l}\text { Salvador } \\
\text { BA }\end{array}$ \\
\hline
\end{tabular}




\begin{tabular}{|l|l|l|l|l|l|}
\hline & $\begin{array}{l}\text { Matemática e os saberes } \\
\text { necessários à profissão docente }\end{array}$ & & & & \\
\hline $\begin{array}{l}\text { D’AMBRÓSIO, } \\
\text { Ubiratan }\end{array}$ & $\begin{array}{l}\text { A educação matemática hoje: } \\
\text { porque e como? }\end{array}$ & $\begin{array}{l}\text { Conferência de } \\
\text { Encerramento }\end{array}$ & XII & 2016 & $\begin{array}{l}\text { São Paulo } \\
\text { SP }\end{array}$ \\
\hline
\end{tabular}

Quadro 2 - Textos selecionados para análise

Fonte: $\mathrm{O}$ autor (2018).

Em sua conferência de abertura "A educação matemática na década de 1990: perspectivas e desafios”, D’Ambrósio dirige a atenção dos ouvintes para a necessidade de preparar um novo professor, frente aos desafios que a década de 1990 teria que assumir em relação ao processo de transição para o terceiro milênio e aos avanços da ciência e da tecnologia que vinha ocorrendo naquele momento histórico em que o papel do professor era colocado em questão: "um professor conscientizado de que seu papel é bem mais amplo e certamente mais nobre do que o mero transmissor de informação" (D’AMBRÓSIO, 1988, p. 6).

Problematizando o saber específico na formação do professor, Mauro Urbano Rogério, da Universidade Federal de Goiás, discute no III ENEM, em 1990, a necessidade de recuperar as individualidades dos cursos de formação de professores, em especial a identidade da Licenciatura em Matemática, lembrando os ganhos pedagógicos que poderiam ser obtidos com a autonomia do professor em poder direcionar uma mesma disciplina aos interesses e finalidades de cada curso.

Observa que, apesar do avanço trazido pela legislação que vedou, a partir de 1984, a matrícula por disciplinas, de alunos ingressantes, ao eliminar o sistema de créditos, "as licenciaturas continuaram atreladas aos interesses da formação do bacharel, a dicotomia entre a formação específica e formação pedagógica permaneceu tão forte quanto antes" (ROGÉRIO, 1990, p.112). Afirma que uma indefinição do que é específico para formar o professor pode gerar problemas na formação. Acredita que alguns princípios fundamentais inerentes à tarefa de ensinar como "conhecer o assunto que leciona, conhecer a natureza do aluno, sendo capaz de identificar e dar tratamento às diferenças individuais, ter domínio das técnicas para se fazer entender”( p. 113), poderiam constituir-se em princípios da formação do professor, para além de outros conhecimentos mais amplos como

\footnotetext{
"o conhecimento da realidade da escola, do meio onde ela se insere, da relevância social do seu trabalho e a consciência da importância dele no resgate do valor da educação como fonte de desenvolvimento social, tecnológico, sobretudo, como fator de libertação do homem através, principalmente da construção de uma sociedade mais humana e mais justa, temas esses que deveriam parte de todas as formações profissionais de cursos de formação universitária (ROGÉRIO, 1990, p. 113).
}

Ao falar dos princípios, o autor refere-se aos pontos que diferenciam a formação dos professores, de outras formações profissionais, pontos que constituem o núcleo epistemológico 
da formação docente. "Não existe um caminho real para a formação do professor, no entanto, a dignificação de sua formação profissional passa pela definição de uma estrutura curricular que o identifique perante outras profissões. Em nossa opinião os princípios aqui estabelecidos avançaram neste sentido" (ROGÉRIO, 1990, p. 114).

No relatório-síntese do G1, sobre a produção do G1(Grupo de Formação e Atualização do Professor de Matemática), discutido em 1995, em Aracaju/SE, no V ENEM, coordenado pela Professora Nilza Eigenheer Bertoni-UNB, com a colaboração dos preletores Estela K. Faiguelernt, Geraldo Perez e Manoel Oriosvaldo de Moura, o grupo argumenta ser preocupante o fato da Prática de Ensino não ter uma operacionalização satisfatória na formação e que disciplinas como Resolução de Problemas e Estudos sobre Representações da Matemática poderiam gerar representações mais adequadas da Matemática aos futuros professores.

Mostrando tendências que caracterizam a Educação Matemática, o grupo considerou como muito importantes estudos que trataram da investigação sobre observação, coleta e utilização de dados sobre aprendizagem da Matemática, constatando a necessidade da formação do professor pesquisador e destacando a crescente incorporação da informática na formação do licenciando, não só nos conteúdos específicos como também no eixo da Educação Matemática. Destaca reconhecimentos que os estudos deram a disciplinas como: Pedagogia, Psicologia, Filosofia, Sociologia, Antropologia etc. que contribuem para melhor identificar o perfil do educador matemático.

Nesse sentido, recomenda um quadro de referência curricular para os cursos de Licenciatura, organizados em torno de três eixos: dos conteúdos específicos, da Educação Matemática e das disciplinas de formação do educador matemático. Tal explicitação, de acordo com o grupo, “abrirá um campo para absorção de especialistas que ocuparão novos espaços ou outros indevidamente preenchidos” (BERTONI, 1995, p. 299). Por último, o G1 considera que tal concepção de licenciatura "deve formar professores para um ensino renovado, mais adequado à sociedade atual" (BERTONI, 1995, p. 300).

O quarto texto examinado foi o estudo apresentado por Dario Fiorentini - FEUNICAMP, "De professor isolado ou plugado para professor conectado: novas perspectivas à formação do professor de Matemática", apresentado na Mesa Redonda "Formação de Professores de Matemática”, do VII ENEM, realizado em 2001, no Rio de Janeiro/RJ. O autor discute modelos de formação a partir da construção de imagens de professores: o isolado e prático, o técnico e plugado e o reflexivo/investigativo. Os dois primeiros, considerados modelos dicotômicos, encontram-se ainda presentes em escolas e universidades. O professor isolado, ou prático, também caracterizado como artesão, produto da tradição pedagógica que 
acredita que ser professor é um dom, uma vocação, saber o conteúdo que irá ministrar é o suficiente, a destreza aprende-se na prática, sem necessidade de uma formação formal. Refratário à atualizações e aperfeiçoamentos, não participa de congressos e não se interessa em trocar experiências com colegas sobre o ensino da Matemática.

O segundo, o professor plugado ou técnico, diferencia-se do perfil anterior e da natureza dos saberes que definem sua identidade profissional. Constrói seu saber a partir de uma ciência rigorosa, no dizer do autor: "uma forte carga inicial de formação teórico-científica e um ano terminal de formação complementar didático-pedagógica e prática" (FIORENTINI, 2001, p. 4).

Neste modelo $3+1$, em que a prática preenche o espaço de treino e experimentação da profissão, a intuição dá lugar à racionalidade técnica, regida por princípios que garantiam mais eficiência na aprendizagem do aluno.

"Se o professor ficar um tempo sem tomar conhecimento dos novos saberes que são produzidos para a profissão docente, ele desatualiza-se ou defasa-se, isto é, deforma-se, devendo ser reciclado (como uma sucata) ou atualizado" (FIORENTINI, 2001, p. 5).

Incapaz de produzir conhecimentos próprios, de constituir-se em sujeito de sua própria formação e poder contribuir no debate público sobre reformas educacionais.

Contrapondo a este modelo, o professor conectado, reflexivo, investigativo e autônomo, frente aos desafios de seu tempo busca continuamente dar novos significados à sua prática e por sentir-se inconcluso busca conexões estabelecendo diálogos, trocando conhecimentos e experiências acerca dos saberes da profissão, fazendo de sua prática "uma experiência formativa"7. "Experiência é tudo o que nos forma ou nos transforma", no dizer de Larrosa (LARROSA, 1996, apud FIORENTINI, 2001, p. 7).

A comunicação científica, "O que sei, quem sou e como atuo? O curso de Licenciatura em Matemática os saberes necessários à profissão docente", de autoria de Ana Clédina Rodrigues Monteiro, apresentada no X ENEM, realizado em 2010, em Salvador/BA, faz críticas à organização curricular da Licenciatura em Matemática de uma universidade pública que afirma em seu projeto pedagógico visar a formação de professores de Matemática para atuar na Educação Básica.

As análises mostram que no curso da Licenciatura em Matemática da referida universidade, o que predomina é quase semelhante ao curso de Bacharelado, ou seja, um forte

\footnotetext{
${ }^{7}$ De acordo com citação de Fiorentini (2001, p. 7), o termo "experiência formativa, cunhado por Larrosa (1996), significa "aquilo que nos passa. Não o que passa, senão o que nos passa" (grifo do autor citado). Um modo diferente de conceber a experiência e dar um novo sentido à docência.
} 
enfoque dado aos conteúdos específicos da Matemática e uma grande desconsideração às disciplinas da educação matemática. "Apesar do curso visar a formação de professores para atuar na Educação Básica, esse campo fica praticamente de fora do currículo proposto" (MONTEIRO, 2010, p. 9). Formação esta que dificulta a construção de saberes adequados ao exercício do magistério e também impede a construção de uma sólida identidade profissional.

O último texto seminal da produção da SBEM veio do mais recente ENEM, o XII ENEM realizado em 2016, em São Paulo/SP e cujo tema central foi "Educação Matemática na contemporaneidade: desafios e possibilidades". Trata-se da palestra proferida por Ubiratan D’Ambrósio, ícone brasileiro da Etnomatemática, no encerramento do evento que discorreu sobre “A educação matemática hoje: porque e como?". Criticando as velhas teorias e práticas, deterministas e hierárquicas, advindas de instrumentais quantitativos, propõe uma escola antenada ao que se passa no mundo capaz de gerar um novo papel ao professor, eliminando o paradigma tradicional (modernidade) de causa e efeito em que o professor ensina (causa) e o aluno aprende (efeito). Se a aprendizagem falhar (efeito), ensina-se novamente (causa). Considerando absurdo atribuir a culpa do fracasso escolar ao professor, ao aluno e à sua família, afirma ser grande injustiça "uma instituição justificar suas deficiências atribuindo culpas, não toca a obsolescência do modelo escolar e dos conteúdos” (D’AMBRÓSIO, 2016, p. 3).

\footnotetext{
Aqueles professores que são meros repetidores de matéria e cobradores do aprendizado da matéria lecionada, não terão condições de competir com seus "colegas eletrônicos" que desempenham tarefas de repetidores de conhecimento congelado, muitas vezes em condições melhores e com mais eficácia que professores de 'carne e osso'. Os 'colegas eletrônicos' não reivindicam melhores salários! Mas o professor, com um novo perfil, não de mero repetidor e cobrador de resultados, é insubstituível (D’AMBRÓSIO, 2016, p. 4).
}

Um professor que "para ensinar" não inclui memorização de técnicas e operações que são muito melhores com o auxílio de máquinas, sobrando-lhe tempo para dedicar-se aos conceituais do novo paradigma de ensino de técnicas e operações, seja utilizando e interpretando gráficos e tabelas para criticar abusos sociais, seja dando espaço à fantasia para mostrar a presença da Matemática em todas manifestações culturais, nas artes, na arquitetura, no design moderno (p. 5).

Em suma, saber ensinar Matemática, hoje, envolve saber tecnologia, estatística, possuir espírito crítico, intuição, criatividade, enfim, arte e ciência apropriada para a docência em um mundo em constante mudança.

Perfil que muito se afasta do "pensador" do século XX, e muito se aproxima das características da escritura que bem retratam o homem do século XXI, descrito por Ítalo Calvino (1990), ao enunciar as "Seis propostas para o próximo milênio: lições americanas", texto 
inacabado que elenca apenas cinco das seis propostas anunciadas ${ }^{8}$.

\section{Considerações finais}

$\mathrm{Na}$ consecução dessa tarefa, nos portamos como curiosos leitores-amadores lendo grande quantidade de estudos que, de diferentes formas, compuseram a produção científica da Educação Matemática, veiculada durante três décadas no maior evento da Sociedade Brasileira de Educação Matemática, o ENEM.

Perguntando como a ideia dos saberes profissionais foi abordada nos estudos selecionados, nesta preliminar avaliação, deparamo-nos com uma rica produção sobre saberes pontuais que retratavam os temas mais discutidos nos diferentes momentos das edições, dentre outros, saberes sobre geometria, álgebra, de matemática recreativa, materiais didáticos, informática, estatística, currículo, avaliação, resolução de problemas, modelagem matemática, alfabetização de adultos, inclusão, interdisciplinaridade, um complexo volume de saberes de experiência à espera de sistematizações, como indicam os mapeamentos e artigos de educadores preocupados com a indefinição identitária da profissão docente.

Nessa leitura, também foi possível constatar relações entre preferências dos organizadores ao definir tema central do evento e distribuição dos trabalhos, ora de forma mais conservadora, ora de forma mais ousada.

Um avanço observado nos informes de algumas edições foram as novas propostas e sugestões, de modo especial, as chamadas feitas por Ubiratan D’Ambrósio nas duas edições do ENEM, expressando anseios do passado e do presente, em relação aos saberes necessários aos professores que ensinam Matemática. Do evento fundador (1987) ao evento mais atual (2016), as mudanças mencionadas parecem ser uma constante no que se refere ao repertório de conteúdos e métodos, porém, pouco inovadoras, como se refere D’Ambrósio (2016), quando trata de propostas que adequem os saberes profissionais aos ditames contemporâneos. Uma surpresa foi o estudo de Mauro Urbano Rogério (1990) que discutiu institucionalização de saberes, apontando o que considerava específico na formação, nos anos de 1990, momento em que o foco do cenário educacional se dirigia aos saberes da experiência e para os processos reflexivos emanados da prática docente.

\footnotetext{
8 "Leveza", "Rapidez", "Exatidão", "Visibilidade" e "Multiplicidade” são cinco conferências que Calvino havia preparado para a Universidade de Harvard e que, devido à morte súbita do autor, nunca foram proferidas. São também cinco das qualidades da escritura (uma sexta, a Consistência, seria o tema da última conferência, jamais escrita) que Calvino teria desejado transmitir à humanidade do milênio que estava por vir.
} 
As demais discussões selecionadas mostram-se unânimes em afirmar que os saberes profissionais não são estáticos, ao contrário, expressam uma atividade social dinâmica que envolve mobilização de conhecimentos variados, concebem a docência como uma prática complexa, uma práxis, muito mais abrangente do que o "dar aula" e contar unicamente com o domínio dos conteúdos matemáticos. Defendem uma fusão de campos disciplinares, da ciência de referência e da ciência da educação, no currículo de formação, a favor, portanto, de uma formação não dispersa e fragmentada, como vem sendo denunciada pelos pesquisadores. Um desafio de grande envergadura para as agências formadoras, por suscitar processos e dinâmicas que expressem o sentido profissional apropriado ao novo século, como sugeriu D’Ambrósio, no discurso do último ENEM, ao indagar se a SBEM está acenando para essa nova realidade, porque e como?

Pelo que indicam as análises um aceno foi dado no III ENEM, realizado em Natal, em 1990, quando, por ocasião do encerramento, o coordenador reivindicava que a discussão da formação do professor permeasse todas as categorias, não permanecendo apenas concentrada em um único espaço de discussão. Seria uma possibilidade de compreender melhor "não aquilo que passa, senão o que nos passa" (LARROSA, 1996, p. 136-137 apud FIORENTINI, 2001, p. 7), isto é, abrir pontes entre o que sabemos e o que somos, tendo em vista, dar um sentido ao nosso fazer, como educadores matemáticos?

Como observou Búrigo, em sua participação nessa mesa comemorativa dos 30 anos da SBEM, "o esvaziamento das licenciaturas, contudo, é um dentre muitos sinais de que avançamos muito pouco - ou quem sabe até regredimos - em relação às condições para se ensinar matemática na escola básica” (BÚRIGO, 2018, p. 22).

Da mesma forma, a chamada dada por Filipe Santos Fernandes, na referida mesa, ao mencionar a responsabilidade pela subjetividade que "o pertencimento à SBEM e ao lastro histórico de sua constituição e atuação permite a elaboração do que somos, de quem somos, do que nos tornamos, de como nos tornamos o que somos, do que não podemos e não queremos ser ou do que já deixamos de ser" (FERNANDES, 2018, p. 17).

A essa altura, após examinar a produção, pergunto se a dificuldade em sistematizar saberes profissionais não seria pelo fato da maioria dos pesquisadores considerar difícil, quase uma missão impossível, conceber saberes para ensinar Matemática, por desconhecer a história de sua própria profissão?

\section{Agradecimentos}


Meus especiais agradecimentos à Comissão Organizadora do VII SIPEM, na pessoa da Profa. Dra. Regina Célia Grando - Presidente da SBEM e Comissão Organizadora Local, na pessoa do Prof. Dr. Rodolfo Eduardo Vertuan - Diretor da SBEM/PR, pela excelente acolhida; aos Coordenadores do GT-15, Grupo de Trabalho da História da Educação Matemática, nas pessoas da Profa. Dra. Maria Cristina Araújo de Oliveira e Antonio Vicente Marafioti Garnica pela oportunidade de compor a Mesa 2: "A Pesquisa em Educação Matemática nos 30 anos da SBEM" e, igualmente, ao Prof. Dr. Wagner Rodrigues Valente, Coordenador do GHEMAT Brasil, pelas sugestões dadas para a construção de minha apresentação na referida mesa.

\section{Referências}

ANDRÉ, M. E. D. A. A produção acadêmica sobre formação de professores: um estudo comparativo das dissertações e teses defendidas nos anos de 1990 e 2000. Revista Brasileira de Pesquisa sobre Formação de Docente. Belo Horizonte, v. 1, n. 1, p. 41-56, ago./dez. 2009. Disponível em: http://formacaodocente.autenticaeditora.com.br/artigo/exibir/1/7/3. Acesso em: 17 mai. 2018.

ANDRÉ, M. Formação de professores: a constituição de um campo de estudos. Educação. Porto Alegre, v.33, n.3, p. 174-181, set/dez. 2010. Disponível em:

revistaseletronicas.pucrs.br/ojs/index.php/faced/article/view/8075. Acesso em: 6 nov. 2019.

BERTONI, N. E. et al. Síntese do G1: Formação e Atualização do Professor de Matemática. In: Encontro Nacional de Educação Matemática, 5, 1995, Aracaju. Anais... Aracaju: UFS/SE, 1995. p. 299-300.

BÚRIGO, E. Z. A Sociedade Brasileira de Educação Matemática e as Políticas Educacionais. In: Seminário Internacional de Pesquisa em Educação Matemática, 7, 2018, Foz do Iguaçú. Anais... Foz do Iguaçú: SBEM, 2018. p. 1-26.

CALVINO, I. Seis propostas para o próximo milênio: lições americanas. São Paulo: Companhia das Letras, 1990.

CERICATO, I. L. A profissão docente em análise no Brasil: uma revisão bibliográfica. Revista Brasileira de Estudos Pedagógicos. Brasília, v. 97, n. 246, p. 273-289, 2016. Disponível em: http://dx.doi.org/10.1590/S2176-6681/373714647. Acesso em: 17 mai. 2018.

CHERVEL, A. História das disciplinas escolares: reflexões sobre um campo de pesquisa. Teoria \& Educação, n.2, p.177-229, 1990.

D'AMBROSIO, U. Apresentação. In: Encontro Nacional de Educação Matemática, 1, 1987, São Paulo. Anais...São Paulo: Atual Editora, 1988. Disponível em:

http://www.sbembrasil.org.br/sbembrasil/index.php/anais/enem. Acesso em: 24 out. 2018.

D'AMBRÓSIO, U. A educação matemática na década de 1990: perspectivas e desafios. In: Encontro Nacional de Educação Matemática, 1, 1987, São Paulo. Anais...São Paulo: Atual Editora, 1987, p.310. Disponível em: http://www.sbembrasil.org.br/sbembrasil/index.php/anais/enem. Acesso em: 24 out. 2018.

D’AMBRÓSIO, U. A Educação Matemática hoje: por que e como? In: Encontro Nacional de Educação Matemática, XII ENEM, 2016, São Paulo. Anais... São Paul: Campus Anália Franco da Universidade Cruzeiro do Sul, São Paulo/SP. Programa de Pós-Graduação em Ensino de Ciências e Matemática da Universidade Cruzeiro do Sul, p. 1-5. Disponível em: 
http://www.sbembrasil.org.br/sbembrasil/index.php/anais/enem. Acesso em: 24 out. 2018.

FERNANDES, F. S. A SBEM, o ensino de matemática e a formação de professores: afinal, quem somos nós? In: Seminário Internacional de Pesquisa em Educação Matemática, 7., 2018, Foz do Iguaçú. Anais... Foz do Iguaçú: SBEM, 2018, p. 1-19.

FIORENTINI, D.; PASSOS, C. L. B.; LIMA, R. C. R. Mapeamento da pesquisa acadêmica brasileira sobre o professor que ensina matemática: período 2001-2012. Campinas, SP: FE/UNICAMP, 2016.

FIORENTINI, D. De professor isolado ou plugado para professor conectado: novas perspectivas à formação do professor de Matemática. In: Encontro Nacional de Educação Matemática, VII ENEM, 2001, Rio de Janeiro. Anais... p.1-11. Disponível em

http://www.sbembrasil.org.br/sbembrasil/index.php/anais/enem. Acesso em: 24 out. 2018.

GATTI, B. A. Formação inicial de professores para a educação básica: pesquisas e políticas educacionais. Estudos em Avaliação Educacional. São Paulo, v. 25, n. 57, p. 24-54, jan./abr., 2014.

HOFSTETTER, R.; SCHNEUWLY, B. Savoirs en (trans)formation - Au cour des professions de l'enseignement et de la formation. Bruxelles: Éditions De Boeck Université, 2009.

HOFSTETTER, R.; VALENTE, W. R. (Orgs.). Saberes em (trans)formação: tema central da formação de professores. São Paulo: Editora Livraria da Física, 2017.

LUSSI BORER, V. Saberes: uma questão crucial para a institucionalização da formação de professores. In: HOFSTETTER, R.; VALENTE, W.R. (Orgs.). Saberes em (trans)formação: tema central da formação de professores. São Paulo: Editora Livraria da Física, 2017, p.173-199.

MONTEIRO, A. C. R. O que sei, quem sou e como atuo? O curso de Licenciatura em Matemática e os saberes necessários à profissão docente. In: Encontro Nacional de Educação Matemática, 10., 2010, Salvador. Anais... Salvador: SBEM/BA, 2010. p. 1-11. Disponível em: http://www.sbembrasil.org.br/sbembrasil/index.php/anais/enem. Acesso em: 29 out. 2018.

NACARATO, A. M. et al. Tendências das pesquisas brasileiras que tem o professor que ensina matemática como campo de estudo: uma síntese dos mapeamentos regionais. In: FIORENTINI, D.; PASSOS, C. L. B.; LIMA, R. C. R. (Org.). Mapeamento da pesquisa acadêmica brasileira sobre o professor que ensina matemática: período 2001-2012. Campinas: FE/UNICAMP, 2016. p. 319-350. Disponível em: https://www.fe.unicamp.br/pf-fe/pf/subportais/biblioteca/fev-2017/e-bookmapeamento-pesquisa-pem.pdf. Acesso em: 23 mai. 2018.

PIMENTA, S. G. Formação de Professores: saberes da docência e identidade do professor. Revista Nuances. São Paulo, v. 3, p. 5-14, set. 1997.

ROGÉRIO, M. U. O que é específico na formação do professor? In: Encontro Nacional de Educação Matemática, 3., 1990, Natal. Anais... Natal: SBEM, 1990. p. 109-114, 1990. Disponível em http://www.sbembrasil.org.br/sbembrasil/index.php/anais/enem. Acesso em 24 de outubro de 201.

TARDIF, M. Saberes docentes e formação profissional. Petrópolis, RJ: Vozes, 2002.

VALENTE, W. R. Quem somos nós, professores de matemática? Caderno Cedes. Campinas, v. 28, n. 74, p. 11-23, jan./abr. 2008.

VALENTE, W. R. Os movimentos da matemática na escola: do ensino de matemática para a educação matemática; da educação matemática para o ensino de matemática; do ensino de matemática para a Educação Matemática; da Educação Matemática para o Ensino de Matemática? Pensar a Educação em Revista, Curitiba/Belo Horizonte, v. 2, n. 2, p. 3-23, abr./jun. 2016. 